\section{EVALUATION OF THE PRACTICAL IMPACT OF SEX EDUATION AMONG GIRL ADOLESCENT STUDENTS- AN EXPERIMENTAL STUDY}

KEY WORDS: Sex education, adolescents, attitude and behaviour towards sex education

\title{
Dr.Suganthi.M
}

Assistant Professor, Department of Social Work, PSG College of Arts \& Science, Coimbatore-641014

Sex education and reproductive health has always been demurred subject in India due to culture and religious inhibitions. Lack of knowledge on reproductive health during adolescent leads to sexually transmitted infections, violence, bullying and unplanned pregnancy ( RM Anderson, 2013).The hormonal changes during the adolescent age, stigma on sex related subject matters and gender inequalities in India are the greater challenges for reproductive health education (WHO,2010). Thus, endowing the scientific knowledge on sex will navigate to a quality life. Considering the above aspects, the study was rolled on to study intends to emphasize the need, knowledge and attitude towards sex education among girl adolescent and also to investigate the positive and negative effect of sex education on students. The study intended to understand the practical possibilities in implementing sex education in India

\section{INTRODUCTION:}

The WHO defines sexual health as a state of physical, emotional, mental and social well being in relation to sexuality and not merely the absence of disease or infirmity (WHO,2006).Sex education is an education on the human sexuality which is quintessence of healthy human relationship ( Neelofar et.al, 2006). The primary aim of sex education is to reinforce sexual knowledge and make childrens' conscious on healthy and deferential choices on relationships, physical and psychological health. The intention of sexuality education concerns has now gained priorities to prevent unwanted pregnancy, prevent sexual transmitted diseases and enlighten children on good and bad touch (WHO \&UNFPA, 2016). In India, sex education has taken twists and turns from decades due its cultural practices.United Nations Children's Fund ( Unicef ) reported that 240 million children are getting married at young age (Hindusthan Times,2021).Sex education for adolescents is remedial to avoid obscene consequences. The age grouping of adolescents as per WHO is from 10 to 19 . The stage of adolescence is the period were tremendous change occurs bodily and psychologically, especially due to the onset of menarche girls are vulnerable ( NIPCCD,2014)

India beginning a growing country with 138 crores with highest youth population is in dreadful state in dealing youth and sex education. India finding difficulty to bridge conservative cultural and modest sex education policy. To reach sustainable development goal, it is seriously essential for India to apprehend its operation in all levels, more significantly among the youth population.

\section{STATEMENT OF PROBLEM:}

The Supreme Court of India in its land mark judgement recognized homosexuality, despite the fact that sex education is still remains to be concealed topic (Simran Bajaj, 2018)Sex education and reproductive health has always been demurred subject in India due to culture and religious inhibitions. Lack of knowledge on reproductive health during adolescentleads to sexually transmitted infections, violence, bullying and unplannedpregnancy ( $R M$ Anderson, 2013).The hormonal changes during the adolescent age, stigma on sex related subject matters and gender inequalities in India are the greater challenges for reproductive health education (WHO,2010). Thus, endowing the scientific knowledge on sex will navigate to a quality life. Considering the above aspects, the study was rolled on to study intends to emphasize the need, knowledge and attitude towards sex education among girl adolescent and also to investigate the positive and negative effect of sex education on students..

\section{OBJECTIVES OFTHE STUDY:}

1. To understand the socio demographic profile of the respondents

2. To understand the knowledge, attitude, and need of sex education among the girl adolescent students using UNESCO questionnaire
3. To educate students on sex education

4. To evaluate by comparing pre \& post experiment scores among the selected respondents

\section{RESEARCH METHODOLOGY:}

The researcher adopted Experimental Research Design study attempting to obtain a complete and accurate information. An experimental study is a research methodology that has commonly used in social science. The universe of the study was Coimbatore district, Tamil Nadu. The target population of the study are the girls aged between 13 to 18 . The sample size is 20 . The sample were selected only from SRI. P. Mallaiyan Matriculation Higher Secondary school, Madukkarai and Shri Narayana guru polytechnic college, Navakarai are the school and college selected for the study. Hence, the sampling technique chosen for the study is Convenient sampling technique under Non probability sampling method is a sampling technique.The type of data collection used by the researcher for the study is interview schedule. The interview schedule comprise of the following:

- Socio demographic characteristics like age, details about parents, type of family, neighbourhoods and so on.

- Structured questionnaires for sex education- Global early baseline survey of UNESCO.UNESCO's memory of the world (MoW) programme was established with the objectives of facilitating preservation, enhancing universal access, and increasing awareness worldwide of the sex education and significance of world's documentary heritage. Questions were pretested and questions suitable for Indian scenario alone were concluded for the final study.

\section{METHOD OF DATA COLLECTION:}

Pre-test was conducted to test the knowledge of the students with structured questionnaires which comprises topics like sexual intercourse, HIV, birth control and so on for 20 respondents in first session.

\section{INTERVENTION:}

Researcher gave intervention about the topics covered in the questionnaires. Researcher help the respondents to gain detailed knowledge about the topics like experience in childhood, unwanted pregnancies, abortion and etc in next session for the 20 respondents.

Post-test was then conducted to test the knowledge of the respondents with the same questionnaires to those 20 respondents.

The data collected from the respondents was coded and edited in SPSS VERSION 16. Since the researcher has used non-probability sampling techniques, non-parametrical test was used for fulfilling the objectives. 


\section{Findings:}

\section{Profile of the respondents:}

All the respondents have their parent consent for collecting data on sex education.Almost all the respondents said that they sleep two in a room, this might be because that most of them are coming from lower income group family and they lack individual room facilities. Moreover, in Indian culture children sleep with their parents. 63.3 percent respondents considertheir religion is important to them. Religious diversity and religious tolerance are both established in the country by the law and custom. Moreover, most respondents are from rural area. 56.7 percent respondents had attended religious activity two or more times in past one month. 33.3 percent of the respondents are living in same area. $36.7 \%$ of respondent's fathers were aged more than 40 years and 6.7 percent of respondent's father were aged between 35 to 39 . 46.7 percent of respondent's fathers have completed secondary. Most of the respondent's father daily wage workers and very few are self-employed. Most of the respondents' mothers (20.0\%) aged between 30 to 45 years. $40 \%$ of the mothers have not completed secondary school, it is evident from this that the women in rural areas lack interest in education. All most all the mothers are daily wage workers. $66.7 \%$ of respondent's mothers are working to secure their children's education and save for the future. All the respondents' parents are living together. $40 \% \& 66 \%$ of the father and mother do not permit the girls to have boyfriends. $63.3 \%$ of the respondents are feeling free to discuss their bodily changes to their caregivers.

\section{Major findings:}

Paired Sample T Test was done to determine the pre and post score of various factors related to the assessing knowledge, attitude and need of sex education among girl adolescent student.

The score of percentage of knowledge on HIV AIDS was low among all the respondents and where as in posttest entire girls found to have obtained substantial knowledge on HIV AIDS.

There was a significant difference in the scores for pre test $(\mathrm{M}=1.65, \mathrm{SD}=0.745)$ and post test score $(\mathrm{M}=1.00, \mathrm{SD}=0.00)$ Conditions; $\mathrm{t}(19)=3.901, \mathrm{P}=0.001)$.

The pre test score on knowledge on sexual intercourse was nil among all the them. Eventually, about 16 out of 20 respondents have gained good score in post score.The result of the paired t test is there was a significant difference in the scores for pre test $(\mathrm{M}=1.00, \mathrm{SD}=0.147)$ and post test score $(\mathrm{M}=2.70, \mathrm{SD}=0.657)$ Conditions; $\mathrm{t}(19)=-11.573, \mathrm{P}=0.00)$.

The acquaintance on birth control is significant as it is found that teenage pregnancy is higher in rural areas comparing to the urban (shobasuri, 2020). Considering the importance of knowledge on birth control was determined, expectedly, the pre test score was found to be very low among all the sample and the post test score is as follows

There is no significant difference in the scores for pretest $(\mathrm{M}=1.00, \mathrm{SD}=0.000)$ and post test score $(\mathrm{M}=1.10, \mathrm{SD}=0.308)$ Conditions; $\mathrm{t}(19)=-1.453, \mathrm{P}=0.163$ ).

Theadolescent girls were inquired on menstruation facts and hygiene periods. In pre testscore about $75 \%$ of them found have very low and $25 \%$ are medium in hygiene period practice and absence of fundamental knowledge on menstruation. The knowledge was imparted on menstruation and the importance of hygiene, later in post score there is no much difference. The score of difference is as follows

There is no significant difference in the scores for pretest $(\mathrm{M}=1.25, \mathrm{SD}=0.44)$ and post test score $(\mathrm{M}=1.25, \mathrm{SD}=0.44)$ Conditions; $\mathrm{t}(19)=0.00, \mathrm{P}=1.000)$.
The adolescent development is segmented in to three i.e., adrenarche, gonad Arche and growth axis (Dorn, et., 2006) At the highest, $65 \%$ of them do not recognize their bodily changes and $35 \%$ do agree to their bodily changes.The scientific knowledge on hormonal chances and bodily development were imparted, the following is the post sccore There is significant difference in the scores for pretest $(\mathrm{M}=1.35, \mathrm{SD}=0.489)$ and post test score $(\mathrm{M}=2.15, \mathrm{SD}=0.671)$ Conditions; $\mathrm{t}(19)=-3.559, \mathrm{P}=0.002)$.

Studies have shown that girls experience abuse than boys ( Pasura et al., 2014, Jones et al.,2010). Body shaming, abuse or teasing is again a considerable problem which exist in society. Assertive approach towards approaching abuse was assessed, it was found that about $65 \%$ of the respondents have experienced some or other way of body shaming or abuse or teasing by other. Evidently, the study conducted on body shaming have reported that about $44.9 \%$ have experienced body shaming (Rahulgam,et al.,2020).The ways and means to approach abuse were thought through role plays as an intervention the results are as follows There is no significant difference in the scores for pretest $(M=2.10$, $\mathrm{SD}=0.912)$ and post test score $(\mathrm{M}=1.65, \mathrm{SD}=0.745)$ Conditions; $\mathrm{t}(19)=1.528, \mathrm{P}=0.143$ )

The knowledge of pregnancy was interpreted among the respondents. There is significant difference in the scores for pretest $(\mathrm{M}=1.90, \mathrm{SD}=0.641)$ and post test score $(\mathrm{M}=1.05, \mathrm{SD}=$ $0.224)$ Conditions; $\mathrm{t}(19)=1.164, \mathrm{P}=0.000)$. United Nations Children's Fund ( Unicef ) reported that 240 million children are getting married at young age (Hindusthan Times,2021). Adolescent pregnancy led to abortion and other adverse health and psychological issues.

\section{DISCUSSION:}

The results indicate that proper knowledge with healthy school environment. Despite the fact that India is second populated country with 253 million population (2011 census) which comprises $21 \%$ of the whole population, the necessity of sex education is essential. A common notion towards sex education in India is increased awareness will bring social stigma .India is finding grim to bridge its indigenous conservative culture and debatable sex education. India have reported high level of sexual abuse and teen-age pregnancy. NCRB report of 2017 have said that 39,827 cases were filed under POCSO ACT in 2018 (India today,2020) i.e., 109 children are getting sexual abused every day. Moreover, to reach Sustainable Development Goal of $3,4 \& 5$, the government has to come up with effective comprehensive sex education as specified by UNESCO. The nation has stepped in to a nice move of beginning National Adolescent Health Programme which gives emphasis on reproductive and sexual health. In India, sex education is a sensitive topic which will only be effective by educating public through civil society organizations (Arrow,2017).To make it success it was advised to reconstruct an inclusive right based language in the CSE curriculum of National Council of Educational Research and Training and UNPF, it was described that the language of the curriculum is ambiguous (Das.Arpita, 2014)

\section{CONCLUSION:}

Social media influence on adolescents are persuaded with incorrect information on sexuality. It is well proved in several studies that media influence teenagers to involve in risky and sexual behaviour ( Buerkel-RothfussNL,et al.,1993;Brown 2001 ;levesque,2007).The sex education is the only source to weed out misconceptions on sex. The world has opened up everything to all without filter has provoked good and bad deeds. It is the responsibility of every element of the society to prepare our future generation to live against unanticipated obstacles of the future.The right information at right time will make youngsters to behave matured and responsible citizen.

\section{REFERENCES}

1. Anderson, R. M. (2013, January 27). Positive sexuality and its impact on overall well-being. Bundesgesundheitsblatt - Gesundheitsforschung Gesundheitsschutz. https://link.springer.com/article/10.1007\%2Fs00103- 
012-1607-z

2. ARROW. (2017). INDIA COMPREHENSIVE SEXUALITY EDUCATION: THE WAY FORWARD. Asian-Pacific Resource \& Research Centre for Women (ARROW) | Sexual \& Reproductive Health and Rights. https://arrow.org.my/wp-content/ uploads/2017/10/India-CSE-brief.pdf

3. Brown, J. D. (2001). Sexual teens, sexual media. https:// doi. org/ 10. 4324/ 9781410604170

4. Buerkel-Rothfuss NL, Strouse JS, Pettey G, et al. Adolescents' and young adults' exposure to sexually oriented and sexually explicit media. In: Greenberg BS, Brown JD, Buerkel-Rothfuss NL, eds. Media, sex and the adolescent. Cresskill (NJ): Hampton Press; 1993: 99-112

5. Das, A. (2014). Sexuality education in India: Examining the rhetoric, rethinking the future. Sex Education, 14(2), 210-224. https:// doi. org/ 10. 1080/14681811.2013.866546

6. Dorn LD (2006): Measuring puberty.J Adolesc Health 39: 625-626.D. Pasura, A. Jones, J. Hafner, P. Maharaj, K. DeCaires, E. JohnsonCompeting meaning of childhood and the social construction of child sexual abuse in the CaribbeanJournal of Childhood, 20 (2) (2014),pp. 200-214

7. Census of India website : Office of the registrar general \& census commissioner, India. (2011). Census of India Website : Office of the Registrar General \& Census Commissioner, India. https://censusindia.gov.in/2011common/censusdata2011.html

8. Gam, R. T., Singh, S. K., Manar, M., Kar, S. K., \& Gupta, A. (2020). Body shaming among school-going adolescents: Prevalence and predictors. International Journal Of Community Medicine And Public Health, 7(4), 1324.https:// doi. org/ 10. 18203/2394-6040.ijcmph20201075

9. India Today. (2020, January 16).109 children sexually abused every day in India in 2018: NCRB. https://www.indiatoday.in/india/story/109-childrensexually-abused-every-day-india-2018-1636160-2020-01-12

10. Improvement in Knowledge and Practices of Adolescent Girls Regarding Reproductive Health with Special Emphasis on Hygiene during Menstruation in Five Years. National Institute of Public Cooperation and Child Development.2014

11. Jones.D, Runyan.D, Lewis.T, Litronik..A, MMTrajectories of childhood sexual abuse and earlyadolescent HIV/AIDS risk behaviours: The role of other maltreatment, witnessed violence and child gender

12. Journal of Clinical Child \& Adolescent Psychology, 39 (5) (2010), pp.667-680

13. Levesque, R. J. (2007). Adolescent sexuality and the media. Adolescents, Media, and the Law, 117-144. https:// doi. org/ 10. 1093/ acprof: oso/ 9780195320442.003 .0005

14. Louis Harris \& Associates, Inc. Sexual material on American network television during the 1987-88 season. New York (NY): Planned Parenthood Federation of America; 1988

15. Neelofar S, Tazeen S: The cultural politics of gender for infertile womenin Karachi, Pakistan. Gender Studies Conference South Africa;2006

16. Suri, S. (2020, January 14).There's a need to end teenage pregnancies in India, it's harming the national economy. ORF. https:// www. orfonline. org/ research/theres-a-need-to-end-teenage-pregnancies-in-india-its-harmingthe-national-economy-60307/

17. WHO \& UNFPA. (2016). Sexuality Education policy brief Nol. https:// WWW. euro. who. int/_-data/ assets/ pdf_file/ 0008/379043/ Sexuality_-education Policy brie No 1.pdf

18. WHO. (2002, January).Defining sexual health Report of a technical consultation on sexual health 28-31 January 2002, Geneva. WHO | World Health Organization. https:// www. who.int/ reproductive health/ topics/ gender rights/defining_sexual_health.pdf 